\title{
The Underrepresentation of Women in Prestigious Ethics Journals
}

\author{
Meena Krishnamurthy \\ Shen-yi Liao \\ Monique Deveaux \\ Maggie Dalecki $<1>$
}

\section{Introduction}

Philosophy has a gender problem. "The gender problem" is, however, a bit of a misnomer, for it is not a single problem. Rather, it is a multifaceted set of problems that relate to the general underrepresentation of women in philosophy - in the historical canon, in the professoriate class and at conferences $<2>$, and in upper-level undergraduate classrooms $<3>$. Our paper investigates one specific aspect of the gender problem that has received relatively little investigation: the underrepresentation of articles by women in top journals. We focus on journal publishing not because we think it is somehow the driving cause of women's underrepresentation in the philosophy professoriate - a problem that surely has many contributing causes, from chilly professional climates and implicit bias in hiring and assessment of research, to job demands that are disadvantageous to women with caregiving responsibilities. Rather, we focus on the issue of journal publishing because we think that if women are underrepresented in top philosophy journals, then this, in and of itself, is a significant aspect of the gender underrepresentation problem. Moreover, it is one that could be expected to have significant implications for women's professional success in the discipline: journals constitute an important currency of academic prestige, and are of the utmost importance for tenure and promotion assessments.

There has been some recent discussion among philosophers of women's representation in prestigious journals, especially prestigious ethics journals, that suggests a gender discrepancy $<4>$. Eric Schwitzgebel and Carolyn Dicey Jennings report that women authored only $13 \%$ of articles (32 out of 249) in "top five" generalist journals in 2014-15 $<5>$. Kathryn Norlock found that between 2009-14, women authors accounted for $17.5 \%$ of published papers in the Journal of Moral Philosophy, and for $20 \%$ of published papers in Ethics $<6>$. Similar numbers have been reported previously. In her study of 7 leading philosophy journals, Sally Haslanger found that women represented $22 \%$ of authors of articles in Ethics, and a mere 13\% in Philosophy and Public Affairs, in the period from 2002-2007 <7>. Thom Brooks, the editor of the Journal of Moral Philosophy at the time, reported in the APA Newsletter that the average number of women-authored papers in this journal between 2003-2009 was 22\%<8>. And Henry S. Richardson, the editor of Ethics, reported that in 2007-2008 women-authored papers in Ethics were at 17\% and in 2008-2009 were at $15 \%<9>$.

While this descriptive data suggests the existence of a gender discrepancy in prestigious ethics journals - our area of focus - it does not suffice to answer the question of whether women are underrepresented in prestigious ethics journals relative to their numbers in the discipline. To establish whether these percentages of women-authored 
publications reflect a gendered discrepancy, we need to compare the data about womenauthored papers with the proportion of women philosophers specializing in ethics. While previous discussions by Haslanger, Healy, Norlock, and Schwitzgebel and Jennings certainly suggest that women authors are underrepresented in prestigious ethics philosophy journals, only this comparative information can help us to establish conclusively whether there is a gender problem specific to journal publishing.

We are drawn to examine specifically whether a gender problem exists in relation to ethics journals because, as we discuss later, conventional wisdom has it that women are disproportionately likely to specialize in ethics $\langle 10>$. (We use "ethics" as an inclusive term for diverse subfields of moral, social, and political philosophy. Section 2 explains our operationalization of the term.) If it turns out that women authors are underrepresented in prestigious ethics journals, a field in which they tend to specialize, then the gender problem in philosophy publishing may be more widespread and pernicious than we thought.

The main goal in this study is, therefore, to determine whether women are underrepresented in prestigious ethics journals relative to their representation in the field of ethics. Our study proceeds in three steps. Step one: we estimate the percentage of women who specialize in ethics. Step two: we estimate the percentage of articles in prestigious ethics journals that are authored by women. Step three: we examine whether there is any difference between the percentage of women who specialize in ethics and the percentage of articles in prestigious ethics journals that are authored by women. We conclude that, overall, women who specialize in ethics are underrepresented in prestigious ethics journals.

\section{Step One: Estimating the Percentage of Women Who Specialize in Ethics}

We used the faculty lists compiled for the Philosophical Gourmet Report (PGR) for the top 50 departments in the period of 2004-2014 to estimate the percentage of women who specialized in ethics. In part, this sampling choice was pragmatic: instead of having to go to many different department websites, the PGR faculty list already has the information in one place. In part, this sampling choice also reflects our sociological recognition that, unfortunately, the philosophical profession is prone to prestige bias: people who work in "top" departments are more likely to publish in "prestigious" journals. As such, if we still found women at these departments to be underrepresented in prestigious journals, that would further strengthen our belief in the existence of underrepresentation more broadly. That is, if women in the most highly-ranked departments are not publishing in the most prestigious journals at a proportionate rate, it seems likely that women outside of this enclave are also not doing so.

We coded for gender on the basis of individuals' first names. Where first names were gender ambiguous, we coded for gender on the basis of information found on the individual's departmental webpages and CVs. We looked for photographs and pronouns used by the individuals to describe themselves. 
We coded for AOS in ethics in a sense that includes diverse subfields of moral, social, and political philosophy. We counted people as specializing in ethics when they listed any of the following as an AOS or a research interest or when they published mostly in any of the following areas: Ethics; Normative Ethics; Social Philosophy; Political Philosophy; Metaethics; Moral Psychology; Feminist Ethics; Bioethics; Environmental Ethics; Naturalistic Ethics; Applied Ethics; Ethical Theory; Academic Ethics; Ethics of Technology; Business Ethics; $19^{\text {th }}$ Century Ethics; Medical Ethics; History of Ethics; Foundations of Ethics; Philosophy of Law; Moral Philosophy; Ancient Ethics; Kantian Ethics; History of Political Philosophy; Aristotelian Ethics.

We determined AOS by searching individuals' departmental and/or personal webpages. AOS was interpreted broadly to include not only what was explicitly listed as "area of specialization" but also what was sometimes listed as "research interests," when no AOS was listed. In rare cases where no area of specialization or no research interests were listed, we deduced whether or not to count individuals as having an AOS of ethics based on the publications listed on their CVs online.

\begin{tabular}{|c|c|c|}
\hline & All Specializations & Ethics Specializations \\
\hline $\mathbf{2 0 0 4 - 2 0 0 5}$ & $(181 / 947) 19.1 \%$ & $(86 / 354) 24.3 \%$ \\
\hline $\mathbf{2 0 0 6 - 2 0 0 8}$ & $(190 / 982) 19.3 \%$ & $(95 / 366) 26.0 \%$ \\
\hline $\mathbf{2 0 0 9 - 2 0 1 0}$ & $(222 / 1001) 22.2 \%$ & $(108 / 380) 28.4 \%$ \\
\hline $\mathbf{2 0 1 1 - 2 0 1 2}$ & $(225 / 994) 22.6 \%$ & $(108 / 377) 28.6 \%$ \\
\hline $\mathbf{2 0 1 3 - 2 0 1 4}$ & $(237 / 992) 23.9 \%$ & $(106 / 363) 29.2 \%$ \\
\hline
\end{tabular}

Table 1. Women in philosophy, 2004-2014.

The results are summarized in Table 1. In section 4, we use this information on gender and specializations to investigate whether women are underrepresented in ethics journals.

Moreover, this information is valuable in itself as a snapshot of the profession, even when we acknowledge its limitation as a sample from only the "PGR Top 50" departments. For example, it allows us to assess the conventional wisdom that, within philosophy, women tend to specialize in ethics more than other areas. On one disambiguation of this conventional wisdom, this means that the gender proportion of philosophers who specialize in ethics is not the same as philosophers who do not specialize in ethics. We can then use the data to assess whether the conventional wisdom, at least on this disambiguation, is true or not.

On a weighted average over the period surveyed, in a given year there are roughly 100 women and 266 men who specialize in ethics $<11>$. By contrast, on a weighted average over the period surveyed, in a given year there are roughly 109 women and 508 men who do not specialize in ethics. There is a significant difference in the gender proportion of philosophers who specialize in ethics versus philosophers who do not specialize in ethics: $X^{2}(1)=12.795, p<0.001$, effect size Cramer's $V=0.114$.

\section{Step Two: Estimating the Percentage of Women-Authored Articles in Ethics Journals}


To estimate the representation of women in prestigious ethics journals, we examined the table of contents of four prominent ethics journals-Ethics, Philosophy and Public Affairs (PPA), Journal of Political Philosophy (JPP), and Journal of Moral Philosophy (JMP) — in the period of 2004-2014. We counted all articles, review essays, discussions, debates, survey articles, and introductions as "publications". We also coded publications for gender on the basis of the author's first name. When first names were gender ambiguous, we coded for gender on the basis of information found on individuals' departmental webpages and CVs. We looked at photographs and pronouns used by the individuals to describe themselves. We counted all articles that had at least one woman author as a woman-authored article. (We recognize that this likely overestimates the number of women authors in ethics journals and we discuss its implication in section 5.)

\begin{tabular}{|c|c|c|c|c|}
\hline & Ethics & $P P A$ & $J P P$ & $J M P$ \\
\hline $\mathbf{2 0 0 4}$ & $(2 / 25) 8.0 \%$ & $(2 / 14) 14.3 \%$ & $(8 / 22) 36.4 \%$ & $(6 / 18) 33.3 \%$ \\
\hline $\mathbf{2 0 0 5}$ & $(6 / 22) 27.3 \%$ & $(2 / 16) 12.5 \%$ & $(6 / 23) 26.1 \%$ & $(7 / 18) 38.9 \%$ \\
\hline $\mathbf{2 0 0 6}$ & $(4 / 22) 18.2 \%$ & $(3 / 16) 18.8 \%$ & $(6 / 27) 22.2 \%$ & $(3 / 19) 15.8 \%$ \\
\hline $\mathbf{2 0 0 7}$ & $(7 / 23) 30.4 \%$ & $(1 / 15) 6.7 \%$ & $(6 / 24) 25.0 \%$ & $(5 / 26) 19.2 \%$ \\
\hline $\mathbf{2 0 0 8}$ & $(4 / 25) 16.0 \%$ & $(6 / 16) 37.5 \%$ & $(4 / 24) 16.7 \%$ & $(4 / 19) 21.1 \%$ \\
\hline $\mathbf{2 0 0 9}$ & $(4 / 22) 18.2 \%$ & $(4 / 13) 30.8 \%$ & $(8 / 24) 33.3 \%$ & $(3 / 27) 11.1 \%$ \\
\hline $\mathbf{2 0 1 0}$ & $(6 / 25) 24.0 \%$ & $(3 / 12) 25.0 \%$ & $(6 / 24) 25.0 \%$ & $(5 / 25) 20.0 \%$ \\
\hline $\mathbf{2 0 1 2}$ & $(4 / 21) 19.0 \%$ & $(4 / 12) 33.3 \%$ & $(4 / 23) 17.4 \%$ & $(7 / 28) 25.0 \%$ \\
\hline $\mathbf{2 0 1 3}$ & $(3 / 23) 13.0 \%$ & $(1 / 10) 10.0 \%$ & $(9 / 23) 39.1 \%$ & $(3 / 24) 12.5 \%$ \\
\hline $\mathbf{2 0 1 4}$ & $(5 / 24) 20.8 \%$ & $(4 / 12) 33.3 \%$ & $(7 / 23) 30.4 \%$ & $(10 / 40) 25.0 \%$ \\
\hline Total & $(4 / 31) 12.9 \%$ & $(1 / 11) 9.1 \%$ & $(10 / 23) 43.5 \%$ & $(7 / 29) 24.1 \%$ \\
\hline $\mathbf{2} W$ & $(49 / 263) \mathbf{1 8 . 6} \%$ & $(31 / 147) \mathbf{2 1 . 1 \%}$ & $(74 / 260) \mathbf{2 8 . 5 \%}$ & $(60 / 273) \mathbf{2 2 . 0} \%$ \\
\hline
\end{tabular}

Table 2. Women-authored articles in prestigious ethics journals, 2004-2014.

The results are summarized in Table 2. In section 4, we use this information on gender and publications to investigate whether women are underrepresented in ethics journals.

\section{Step Three: Examining Underrepresentation of Women Ethicists in Ethics Journals}

We used the data from section 2 and section 3 to compare the percentage of articles that are authored by women with the percentage of women who specialize in ethics. For all statistical analyses in this section, we treated each year as a data point for comparisons $<12>$. In our analysis, we used paired-sample t-tests (reported as $t$ statistics) primarily, and Wilcoxon signed-rank tests (reported as $T$ statistics) as a secondary robustness check $<13>$.

\begin{tabular}{|r|r|r|r|r|r|r|r|}
\hline & \multicolumn{2}{|c|}{ \% of women in philosophy } & \multicolumn{3}{|c|}{ \% of women-authored articles in prestigious ethics journals } \\
\hline & All & & In Ethics & Aggregated & Ethics & $P P A$ & \multicolumn{2}{|c|}{$J P P$} & $J M P$ \\
\hline $\mathbf{2 0 0 4}$ & $19.1 \%$ & $\mathbf{2 4 . 3 \%}$ & $\mathbf{2 2 . 8 \%}$ & $8.0 \%$ & $14.3 \%$ & $36.4 \%$ & $33.3 \%$ \\
\hline $\mathbf{2 0 0 5}$ & $19.1 \%$ & $\mathbf{2 4 . 3 \%}$ & $\mathbf{2 6 . 6 \%}$ & $27.3 \%$ & $12.5 \%$ & $26.1 \%$ & $38.9 \%$ \\
\hline $\mathbf{2 0 0 6}$ & $19.3 \%$ & $\mathbf{2 6 . 0 \%}$ & $\mathbf{1 9 . 0} \%$ & $18.2 \%$ & $18.8 \%$ & $22.2 \%$ & $15.8 \%$ \\
\hline $\mathbf{2 0 0 7}$ & $19.3 \%$ & $\mathbf{2 6 . 0} \%$ & $\mathbf{2 1 . 6 \%}$ & $30.4 \%$ & $6.7 \%$ & $25.0 \%$ & $19.2 \%$ \\
\hline $\mathbf{2 0 0 8}$ & $19.3 \%$ & $\mathbf{2 6 . 0 \%}$ & $\mathbf{2 1 . 4 \%}$ & $16.0 \%$ & $37.5 \%$ & $16.7 \%$ & $21.1 \%$ \\
\hline $\mathbf{2 0 0 9}$ & $22.2 \%$ & $\mathbf{2 8 . 4 \%}$ & $\mathbf{2 2 . 1 \%}$ & $18.2 \%$ & $30.8 \%$ & $33.3 \%$ & $11.1 \%$ \\
\hline $\mathbf{2 0 1 0}$ & $22.2 \%$ & $\mathbf{2 8 . 4 \%}$ & $\mathbf{2 3 . 3 \%}$ & $24.0 \%$ & $25.0 \%$ & $25.0 \%$ & $20.0 \%$ \\
\hline $\mathbf{2 0 1 1}$ & $22.6 \%$ & $\mathbf{2 8 . 6 \%}$ & $\mathbf{2 2 . 6 \%}$ & $19.0 \%$ & $33.3 \%$ & $17.4 \%$ & $25.0 \%$ \\
\hline $\mathbf{2 0 1 2}$ & $22.6 \%$ & $\mathbf{2 8 . 6 \%}$ & $\mathbf{2 0 . 0 \%}$ & $13.0 \%$ & $10.0 \%$ & $39.1 \%$ & $12.5 \%$ \\
\hline $\mathbf{2 0 1 3}$ & $23.9 \%$ & $\mathbf{2 9 . 2 \%}$ & $\mathbf{2 6 . 3 \%}$ & $20.8 \%$ & $33.3 \%$ & $30.4 \%$ & $25.0 \%$ \\
\hline
\end{tabular}




\begin{tabular}{|l|r|r|r|r|r|r|r|}
$\mathbf{2 0 1 4}$ & $23.9 \%$ & $\mathbf{2 9 . 2} \%$ & $\mathbf{2 3 . 4} \%$ & $12.9 \%$ & $9.1 \%$ & $43.5 \%$ & $24.1 \%$ \\
\hline
\end{tabular}

Table 3. Side-by-side view of percentages of women in philosophy and percentages of women-authored articles in prestigious ethics journals. Highlighted in gray is the key comparison, between the percentages of women specializing in ethics and the percentages of women-authored articles in prestigious ethics journals.

The main goal in this study is to determine whether women are underrepresented in prestigious ethics journals relative to their representation in the field of ethics. The key analysis thus compares the mean proportion of women specializing in ethics in the 20042014 period, $27.1 \%(S D=2.0 \%)$, with the mean proportion of women-authored articles in prestigious ethics journals in the 2004-2014 period, $22.6 \%(S D=2.3 \%)$. We found a statistically significant difference between the proportion of women-authored articles in prestigious ethics journals and the proportion of women specializing in ethics: $t(10)=$ 5.067, $p<0.001 ; T=2, p=0.003$. Women who specialize in ethics are indeed underrepresented in prestigious ethics journals.

Just for context, we also compared the mean proportion of women in philosophy with all specializations in the $2004-2014$ period, $21.2 \%(S D=1.9 \%)$, with the mean proportion of women-authored articles in prestigious ethics journals in the 2004-2014 period. We did not find a statistically significant difference: $t(10)=1.739, p=0.113 ; T=19, p=0.240$.

To further explore the dataset, we examined each of the four journals separately $<14>$.

First, we looked at Ethics. The mean of proportion of women-authored articles in Ethics in the $2004-2014$ period is $18.9 \%(S D=6.6 \%)<15>$. We found a statistically significant difference between the proportion of women-authored articles in Ethics and the proportion of women specializing in ethics: $t(10)=-3.903, p<0.001 ; T=4, p=0.007$.

Second, we looked at Philosophy and Public Affairs. The mean of proportion of womenauthored articles in PPA in the 2004-2014 period is $21.0 \%(S D=11.3 \%)$. We did not find a statistically significant difference between the proportion of women-authored articles in PPA and the proportion of women specializing in ethics: $t(10)=-1.875, p=0.090 ; T=$ $15, p=0.123$.

Third, we looked at Journal of Political Philosophy. The mean of proportion of womenauthored articles in JPP in the 2004-2014 period is $28.7 \%(S D=8.7 \%)$. We did not find a statistically significant difference between the proportion of women-authored articles in JPP and the proportion of women specializing in ethics: $t(10)=0.579, p=0.575 ; T=26$, $p=0.577$.

Fourth, we looked at Journal of Moral Philosophy. The mean of proportion of womenauthored articles in JMP in the 2004-2014 period is 22.4\% $(S D=8.3 \%)$. We did not find a statistically significant difference between the proportion of women-authored articles in JMP and the proportion of women specializing in ethics: $t(10)=-1.683, p=0.123 ; T=$ $16, p=0.147$.

\section{General Discussion}




\subsection{The Underrepresentation of Women in Prestigious Ethics Journals}

Our study began with the question of whether women are underrepresented in prestigious ethics journals relative to their representation in the field of ethics. Our central finding is that, yes, overall, women are underrepresented in prestigious ethics journals.

We also explored whether underrepresentation appeared in any particular prestigious ethics journal. We did find that underrepresentation occurred in Ethics, which is perhaps the most prestigious of the journals we surveyed. But we did not find that underrepresentation occurred in Philosophy and Public Affairs, Journal of Political Philosophy, or Journal of Moral Philosophy.

Two familiar adages about statistical inference are worth emphasizing in this context. First, a statistically nonsignificant result is not itself evidence for the null hypothesis $<16>$. So, in this context, one should not interpret the nonsignificant results as indicating appropriate gender representation in Philosophy and Public Affairs, Journal of Political Philosophy, or Journal of Moral Philosophy. Second, the difference between statistically significant and nonsignificant may not be statistically significant: in comparing various results, it is a mistake to do so via their statistical significance versus nonsignificance as if there were a sharp difference between the two $<17>$. So, in this context, while the underrepresentation was statistically significant for Ethics but not for Philosophy and Public Affairs and Journal of Moral Philosophy, there is no statistical difference between the three journals. However, there is a statistically significant difference between the proportions of women-authored articles in Ethics and in Journal of Political Philosophy.

We wanted to present these exploratory analyses to acknowledge the complexity of this phenomenon. Honest examinations of real-world phenomena rarely offer a cut-and-dry picture, especially given standard concerns about variation and sampling. Given how few articles each journal publishes per year, it is to be expected that there is considerable variation from year to year within any given journal. It is, for this reason, more difficult to draw any firm conclusions on the basis of the disaggregated data about particular journals. Nevertheless, we do want to emphasize the central finding: women are undoubtedly underrepresented in prestigious ethics journals as a whole.

In establishing the central finding, it is also worth emphasizing our overall conservative approach in this investigation. For example, in estimating the percentage of womenauthored publications, we counted publications as woman-authored as long as there was one woman author. This likely overestimated the proportion of women authors in prestigious ethics journals. Thus, women are likely to be even more underrepresented than our findings suggest. For another example, our use of the PGR faculty list sample in estimating the percentage of women who specialize in ethics is also conservative. Over the periods investigated, we found percentages that range from $24.3 \%$ to $29.2 \%$. For comparison, Schwitzgebel and Jennings estimated the percentage of women specializing in value theory to be $34 \%<18>$. Furthermore, given the existence of prestige bias, women faculty in the top 50 departments are even more likely than those outside to 
publish in prestigious journals. This again makes it the case that women authors are perhaps even more underrepresented across the field than our findings suggest.

\subsection{Potential Explanations and Questions for Future Research}

Our goal was to establish the existence of a phenomenon, namely, that of women underrepresentation in prestigious ethics journals. That leaves open the question of what causes this phenomenon. We now outline some questions that we hope will be addressed in future studies on this topic.

First, might some of the gendered discrepancy be caused by certain prestigious journals in Anglo American analytic philosophy defining ethics too narrowly? By comparison, we used a very broad definition of what counts as ethics in our study; insofar as the editors of some prestigious journals do not share our broad criteria, they may consider scholarship by women we are counting as ethics faculty/researchers as ineligible for publication in their journals. This is certainly concerning. Of particular concern is that prestigious ethics journals may view feminist social criticism and feminist political philosophy, which is largely authored by women, as falling outside the scope of their publications. This would not be surprising, as feminist scholarship in other fields in philosophy, such as epistemology, has notably been sidelined from the leading journals $<19>$. If this is also the case for feminist ethics and feminist social/political philosophy, then this could contribute to the underrepresentation of women authors in prestigious ethics journals, such as Ethics.

Second, what role might professional status play in women's underrepresentation? Women's success with publishing in prestigious ethics journals may depend in part on their professional status: women in continuing positions may be more likely to publish in prestigious ethics journals to a degree proportionate to their numbers in their field. This is something that future studies should delve more deeply into, in order to get a clearer sense of whether very junior members of our profession possibly face structural barriers to publishing in prestigious journals. Our study did not differentiate between assistant, associate, and full professors in determining the relative success of women in journal publishing, but only counted those in tenure/tenure-track positions. Yet, this could potentially be significant, since there is substantial evidence that women philosophers are clustered in the assistant and associate professor ranks, while being dramatically underrepresented among full professors $\langle 20>$. A possible confounding factor here is the status or standing of (tenured and tenure-track) women authors' home departments, since women are less likely to become full professors in the most prestigious philosophy programs $<21>$.

The prospect that professional status and the standing of one's department may impact one's success in publishing in prestigious ethics journals may strike some readers as surprising or even scandalous, given that the four journals we studied have blind review processes in place. However, as editors and reviewers of journal articles will be well aware, there are numerous ways in which the identity and institution of authors may be revealed in the review process. It seems possible that such identification (e.g., by an 
associate or assigning editor) could work against women authors: in Haslanger's study, for example, $84.5 \%$ of men versus only $72.5 \%$ of women reported that their most influential publication was published through submission to a peer-reviewed journal $<22>$. It is possible that informal identification of authors could also disadvantage philosophers from less prestigious institutions - including those from non-English speaking universities that are not well known outside their own countries. Of possible significance here is the fact that at least some of the journals we studied have a system of desk-rejection in place. Where the author's name and institution is known by the editor(s) vetting articles for review or else desk-rejection, implicit bias and favoritism can come into play. For example, it has been claimed that Philosophy and Public Affairs publishes a preponderance of articles by philosophers at Oxford, Harvard, and Princeton $<23>$, potentially reflecting the academic links of its editorial members.

Third, what role might article type play in causing underrepresentation? Our study is not fine-grained enough to tell us whether women might be represented differently in relation to different types of journal publications. It does not control for different types of journal publications, nor for invited versus non-invited articles. The common view is that women tend to publish more in invited venues than other venues. It is held that women are better at maintaining relationships and have a tendency to work through informal networks, which in turn leads to a greater number of invited publications. While this may be the commonly held view, it has not been thoroughly investigated.

Fourth, what role might negative experiences with the review process itself, actual or anticipated, play in the underrepresentation of women? Are women philosophers simply opting not to send their work to the most prestigious journals $<24>$ ? Do they opt out more often than men? If so, why? Liam Kofi Bright suggests that, at least, in the field of science and, perhaps, more generally, women do opt out — or publish less than men because "women concentrate on producing high quality papers in response to an expectation that their work will receive greater scrutiny. Whether or not this expectation is accurate, producing such work is time consuming, so women then produce fewer papers overall" $<25>$. There is evidence supporting this hypothesis in the field of economics: a recent study found that among the top four economics journals, womenauthored papers consistently received more critical reviews, resulting in significantly protracted review processes, delayed publication, and thus "lower research outputs" at a critical time in their careers $<26>$. Determining whether women opt out of submitting to top ethics journals for fear of excessively negative reviews, desk-rejection, or a protracted resubmission process is, however, difficult. This is chiefly because the journals that we surveyed do not collect submission data $<27>$. So, an authors' survey or questionnaire might have to be used to more fully determine whether women have the tendency to opt out of prestigious ethics journals. Among other things, this question of "opting out" would presumably need to be considered in tandem with the question (discussed above) of whether the editors and reviewers of top ethics journals view feminist ethics and feminist social and political philosophy as unfitting subject matter for these journals, and also whether reviewers chosen take a similarly dim view of these topics. There is certainly evidence that mainstream prestigious ethics journals do not publish much feminist work: Haslanger's study of leading philosophy journals between 2002-2007 
found that Philosophy \& Public Affairs published only 4 feminist philosophy articles (out of 78), and Ethics published a mere 3 (out of 105 articles) $<28>$. We need to know whether this is because of editorial decisions, or feminist philosophers opting not to submit their work, or both.

The goal of this study was to determine whether women were underrepresented in prestigious ethics journals, as a whole. We have shown that they were. This finding raises many questions, some of which are about what leads to this underrepresentation. We hope that this preliminary work will stimulate a broader discussion of women's underrepresentation in prestigious ethics journals, and how it relates to other aspects of the gender problem in philosophy.

\section{End Notes}

$<1>$ The authors are equal contributors. Krishnamurthy conceived of and designed the study, Dalecki collected the data, Liao analyzed the data, Deveaux related the findings to other studies of women in ethics, and everyone wrote the paper.

$<2>$ Paxton et al 2012; Jennings 2016; Schwitzgebel, "2015; "Gendered Conference Campaign," Feminist Philosophers, 2009.

$<3>$ Paxton, 2012.

$<4>$ Healy 2015; Krishnamurthy 2014; Krishnamurthy 2017; Schwitzgebel and Jennings 2017.

$<5>$ Schwitzgebel and Jennings 2017.

$<6>$ Norlock 2014.

$<7>$ Haslanger 2008.

$<8>$ Brooks 2010, 16 .

$<9>$ Richardson 2010, 19. More recently, Richardson $(2016,2)$ has noted that there has been a "marked" rise in manuscripts submitted to Ethics in recent years "on issues of gender, sexual ethics and sexual orientation, and race," but that, given the low acceptance rate of the journal generally, this rise "has as yet resulted in only a modest increase in number of articles we have published in these areas." One might infer from this purported increase (Richardson does not provide data here) that the journal has seen an uptick in the publication of articles by women, but our own survey does not bear this out.

$<10>$ Schwitzgebel and Jennings, 2017; Haslanger 2009, 3. We also examine one disambiguation of this conventional wisdom later.

$<11>$ The averages are weighted by year such that, for example, the numbers from the 
(three-year) 2006-2008 period is given 1.5 times the weight of the numbers from the (two-year) 2014-2015 period. We chose to use a difference-of-proportions test with the weighted averages rather than, say, a regression analysis because the year-to-year numbers are not independent, especially since in any given year there are likely to be relatively few cases of faculty turnovers.

$<12>$ It is a conceptually difficult question whether the samples being compared are independent or not. On the one hand, they are estimating quite different things: the proportion of women-authored articles and the proportion of women in the profession, especially for the ethics specializations. On the other hand, there is obviously a relationship between those two things. This conceptual difficulty ramifies into a difficulty for choosing appropriate statistical tests for our substantive hypotheses. In this paper, we chose to treat the samples as dependent and thus used paired-sample t-tests and Wilcoxon signed-rank tests on the respective proportions being estimated for the analyses. $<13>$ We do this because our sample violates the normality assumption of paired-sample t-test. Although t-tests are generally relatively robust to violations of assumptions, the Wilcoxon signed-rank test - as its nonparametric equivalent —offers a helpful check on the robustness of the results. For both tests, we report the two-sided p-values and adopt the conventional statistical significance level of $\alpha=0.05$.

$<14>$ Since there are four comparisons investigated, we used a Bonferroni correction to set the threshold for statistical significance at $p=0.0125$ in order to maintain the conventional statistical significance level of $\alpha=0.05$. We report uncorrected $p$-values in text.

$<15>$ Attentive readers will notice small discrepancies between the percentages reported here and the percentages reported in the "Total" row in Table 2. These discrepancies arise because, as noted, each year is treated as a data point for the analysis. Hence, the percentages reported here represent averages of the yearly proportion of women-authored articles in a journal. In contrast, the percentages reported in the "Total" row in Table 2 represent the proportion of women-authored articles in a journal for the entire 2004-2014 period. These small discrepancies are due to the fact that the total number of articles published in a journal does not stay exactly the same year after year. Although these discrepancies are small, and do not affect our analyses, we report both for completeness.

$<16>$ Hoenig and Heisey 2001.

$<17>$ Gelman and Stern 2006.

$<18>$ Schwitzgebel and Jennings 2017.

$<19>$ See for example Rooney 2010.

$<20>$ Schwitzgebel and Jennings 2017.

$<21>$ In their study, Schwitzgebel and Jennings (2017) found that "women were 
considerably less likely to have full professor rank in PGR-ranked $\mathrm{PhD}$ departments than assistant or associate rank"; see also Haslanger 2008, 322.

$<22>$ Based on 1072 author replies to this question; see Haslanger 2009, 4.

$<23>$ Leiter 2015 .

$<24>$ See also Haslanger 2008, 215.

$<25>$ Bright, Forthcoming.

$<26>$ Hengel 2016. Interestingly, this study also found that article abstracts by women in the leading 4 economics journals were better written than abstracts by male authors, which she suggests is because "referees apply higher standards to female-authored papers" (Hengel 2016, 29).

$<27>$ We emailed the editors of all of the prestigious ethics journals surveyed here to see if they collected submission data. None of them did at the time of asking.

$<28>$ Haslanger 2008, 220.

\section{References}

Bright, Liam Kofi . Decision Theoretic Model of the Productivity Gap. Erkenntnis. Forthcoming.

Brooks, Thom. 2010. The View from the Journal of Moral Philosophy. APA Newsletter. Fall 2010, 10 (1).

Gelman, Andrew and Hal Stern. 2006. The Difference Between 'Significant' and 'Not Significant' is not Itself Statistically Significant. The American Statistician 60 (4): 328331.

2009. Gendered Conference Campaign. Feminist Philosophers. December 10.

https://feministphilosophers.wordpress.com/gendered-conference-campaign/ (accessed February 28, 2017).

Haslanger, Sally. 2008. Changing the Ideology and Culture of Philosophy: Not by Reason (Alone). Hypatia 23 (2): 210-223.

Haslanger, Sally. 2009. Preliminary Report of the Survey on Publishing in Philosophy. The Committee on the Status of Women in the Profession. APA Committee on the Status of Women. December. http://www.mit.edu/ shaslang/papers/HaslangerPRSPP.pdf (accessed February 28, 2017)

Healy, Kieran . 2015. Gender and Citation in Four General-Interest Philosophy Journals, 1993-2013. Feb. 25. https://kieranhealy.org/blog/archives/2015/02/25/gender-and- 
citation-in-four-general-interest-philosophy-journals-1993-2013/ (accessed February 28, 2017).

Hengel, Erin. 2016. Publishing While Female: Gender Differences in Peer Review Scrutiny. Unpublished Manuscript. http://www.erinhengel.com/research/publishing_female.pdf. (accessed February 28, 2017)

Hoenig John M. and Dennis M. Heisey. 2001. The Abuse of Power: The Pervasive Fallacy of Power Calculations for Data Analysis. The American Statistician 55(1): 1-6.

Jennings, Carolyn Dicey. 2016. Women in Philosophy 2004-2014: Which Programs Do Best? New Apps, May 21. http://www.newappsblog.com/2016/05/women-in-philosophy2004-2014-which-programs-do-best.html\#more (accessed February 28, 2017).

Paxton, Molly, Figdor, Carrie and Valerie Tiberius. 2012. Quantifying the Gender Gap: An Empirical Study of the Underrepresentation of Women in Philosophy. Hypatia 27(4): 949-957.

Krishnamurthy, Meena. 2014. Thoughts on the Gender Ratios of Papers Published in Ethics and the Journal of Moral Philosophy. Philosop-her. August 25.

Krishnamurthy, Meena. 2017. Proportionate Representation of Women in Elite Ethics Journals: To Quota or Not to Quota? Public Affairs Quarterly. Forthcoming.

Leiter, Brian. 2015. Editorial practices at Philosophy \& Public Affairs. March 23. http://leiterreports.typepad.com/blog/2015/03/editorial-practices-at-philosophy-publicaffairs.html (accessed February 28, 2017).

Norlock, Kathryn. 2014. Gender Ratios of Papers Published in Ethics and the Journal of Moral Philosophy. New Apps, August 19. http://www.newappsblog.com/2014/08/genderratios-of-papers-published-in-ethics-and-the-journal-of-moral-philosophy.html (accessed February 28, 2017).

Richardson, Henry S. 2010. The Triply Anonymous Review Process at Ethics. APA Newsletter, 10 (1).

Richardson, Henry S. 2016. Editorial: Changes at the Journal. Ethics 127 (1): 1-5.

Rooney, Phyllis. 2010. The Marginalization of Feminist Epistemology and What that Reveals about Epistemology 'Proper'. In Feminist Epistemology and Philosophy of Science: Power in Knowledge, ed. Heidi Grasswick. New York: Springer, pp. 3-24.

Schwitzgebel, Eric. 2015. "Percentage of Women at APA Meetings, 1955, 1975, 1995, 2015." The Splintered Mind, November 17. http://schwitzsplinters.blogspot.com/2015/11/percentage-of-women-at-apa-meetings.html (accessed February 28, 2017). 
Schwitzgebel, Eric and Carolyn Dicey Jennings. 2017. Women in Philosophy:

Quantitative Analyses of Specialization, Prevalence, Visibility, and Generational Change.

Public Affairs Quarterly. Forthcoming. 